\title{
ADVANCED HYBRID PARTICULATE COLLECTOR
}

Quarterly Technical Report

Reporting Period Start Date: 05/01/98 End Date: 09/30/98

Report Issue Date: 11/13/98

DE-AC22-95PC95258--09

Energy \& Environmental Research Center

University of North Dakota

PO Box 9018

Grand Forks, ND 58202-9018 


\section{DISCLAIMER}

This report was prepared as an account of work sponsored by an agency of the United States Government. Neither the United States Government, nor any agency thereof, nor any of their employees makes any warranty, express or implied, or assumes any legal liability or responsibility for the accuracy, completeness, or usefulness of any information, apparatus, product, or process disclosed or represents that its use would not infringe privately owned rights. Reference herein to any specific commercial product, process, or service by trade name, trademark, manufacturer, or otherwise does not necessarily constitute or imply its endorsement, recommendation, or favoring by the United States Government or any agency thereof. The views and opinions of authors expressed herein do not necessarily state or reflect those of the United States Government or any agency thereof.

\section{EERC DISCLAIMER}

LEGAL NOTICE This research report was prepared by the Energy \& Environmental Research Center (EERC), an agency of the University of North Dakota, as an account of work sponsored by Federal Energy Technology Center. Because of the research nature of the work performed, neither the EERC nor any of its employees makes any warranty, express or implied, or assumes any legal liability or responsibility for the accuracy, completeness, or usefulness of any information, apparatus, product, or process disclosed, or represents that its use would not infringe privately owned rights. Reference herein to any specific commercial product, process, or service by trade name, trademark, manufacturer, or otherwise does not necessarily constitute or imply its endorsement or recommendation by the EERC. 


\title{
ADVANCED HYBRID PARTICULATE COLLECTOR
}

\begin{abstract}
A new concept in particulate control, called an advanced hybrid particulate collector (AHPC), is being developed under funding from the U.S. Department of Energy. The AHPC combines the best features of electrostatic precipitators (ESPs) and baghouses in a manner that has not been done before. The AHPC concept consists of a combination of fabric filtration and electrostatic precipitation in the same housing, providing major synergism between the two collection methods, both in the particulate collection step and in transfer of the dust to the hopper. The AHPC provides ultrahigh collection efficiency, overcoming the problem of excessive fineparticle emission with conventional ESPs, and it solves the problem of reentrainment and collection of dust in conventional baghouses.
\end{abstract}




\section{TABLE OF CONTENTS}

LIST OF FIGURES $\ldots \ldots \ldots \ldots \ldots \ldots \ldots \ldots \ldots \ldots \ldots \ldots \ldots \ldots \ldots$

EXECUTIVE SUMMARY $\ldots \ldots \ldots \ldots \ldots \ldots \ldots \ldots \ldots \ldots \ldots \ldots$ iii

1.0 PHASE II PLANNED WORK $\ldots \ldots \ldots \ldots \ldots \ldots \ldots \ldots \ldots \ldots \ldots \ldots \ldots \ldots \ldots \ldots \ldots \ldots$

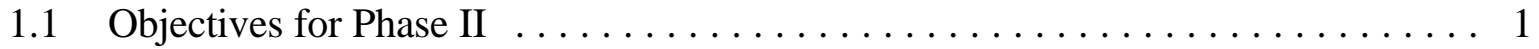

1.2 Phase II Statement of Work $\ldots \ldots \ldots \ldots \ldots \ldots \ldots \ldots \ldots \ldots \ldots \ldots \ldots \ldots$

1.2.1 Task 1 - Project Management and Reporting ................ 1

1.2.2 Task $2 \mathrm{a}$ - Additional $5.7-\mathrm{m}^{3} / \mathrm{min}(200-\mathrm{acfm})$ Tests $\ldots \ldots \ldots \ldots \ldots \ldots$

1.2.3 Task $2 b$ - Design of $255-\mathrm{m}^{3} / \mathrm{min}$ (9000-acfm) Field Demonstration AHPC 2

1.2.4 Task $2 \mathrm{c}-$ Construction and Installation of $255-\mathrm{m}^{3} / \mathrm{min}(9000-\mathrm{acfm})$ Unit . . 2

1.2.5 Task 3 - Field Testing of $255-\mathrm{m}^{3} / \mathrm{min}(9000-\mathrm{acfm})$ Unit . . . . . . . . . . 2

2.0 PROJECT STATUS AND RESULTS $\ldots \ldots \ldots \ldots \ldots \ldots \ldots \ldots \ldots \ldots \ldots \ldots \ldots \ldots \ldots$

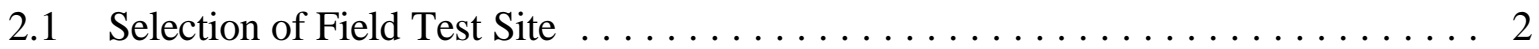

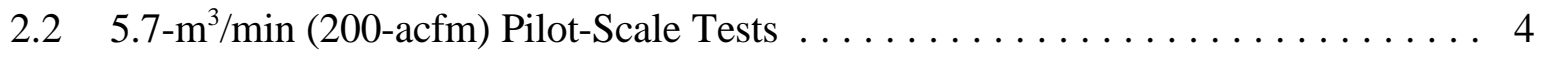

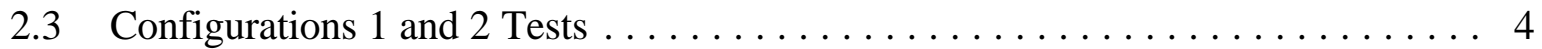

2.4 Design, Construction, and Testing of $255-\mathrm{m}^{3} / \mathrm{min}(9000-\mathrm{acfm}) \mathrm{AHPC} \ldots \ldots \ldots 5$

\section{LIST OF FIGURES}

$1 \quad$ Particle-size distribution at the ESP inlet $\ldots \ldots \ldots \ldots \ldots \ldots \ldots \ldots \ldots \ldots \ldots$

2 AHPC pressure drop and ESP current for Runs 598 and $599 \ldots \ldots \ldots \ldots \ldots$

3 AHPC pressure drop and ESP current for Run $600 \ldots \ldots \ldots \ldots \ldots \ldots \ldots$

$4 \quad$ Bag-cleaning interval for Run $600 \ldots \ldots \ldots \ldots \ldots \ldots \ldots \ldots \ldots \ldots \ldots \ldots \ldots \ldots \ldots$ 


\section{ADVANCED HYBRID PARTICULATE COLLECTOR}

\section{EXECUTIVE SUMMARY}

A new concept in particulate control, called an advanced hybrid particulate collector (AHPC), is being developed at the Energy \& Environmental Research Center (EERC) with U.S. Department of Energy (DOE) funding. The AHPC combines the best features of electrostatic precipitators (ESPs) and baghouses in a manner that has not been done before. The AHPC concept combines filtration and electrostatics in the same housing, providing major synergism between the two collection methods, both in the particulate collection step and in transfer of dust to the hopper. The AHPC provides ultrahigh collection efficiency, overcoming the problem of excessive fine-particle emissions with conventional ESPs, and solves the problem of reentrainment and recollection of dust in conventional baghouses.

The objective of the project is to develop a highly reliable AHPC that can provide $>99.99 \%$ particulate collection efficiency for particle sizes from 0.01 to $50 \mu \mathrm{m}$, is applicable for use with all U.S. coals, and is cost-competitive with existing technologies.

Phase I of the development effort consisted of design, construction, and testing of a 5.7- $\mathrm{m}^{3} / \mathrm{min}$ (200-acfm) working AHPC model. Results from both 8-hr and 100-hr tests show that the concept works well, achieving greater than $99.99 \%$ collection efficiency for fine particles at high filtration velocities.

Phase I started at Maturity Level I, an idea with no supportive experimental data, and progressed smoothly from the design and construction of the $5.7-\mathrm{m}^{3} / \mathrm{min}(200$-acfm) model through 100-hr proof-of-concept tests at the subscale level. Since all of the developmental goals of Phase I were met, the approach is being scaled up in Phase II. Additional $5.7 \mathrm{~m}^{3} / \mathrm{min}$ (200-acfm) tests were conducted as part of the Phase II effort to help optimize the scaled up design. For Phase II, a size of $255 \mathrm{~m}^{3} / \mathrm{min}$ (9000 acfm) was selected as the best combination of being large enough to allow meaningful tests with full-scale components, but yet small enough to be transportable and cost-effective. A scaleup in size by a factor of 45 and an increase in the test time to 5000 hours is a large developmental step that presents some risk, but the Phase I results looked highly promising so the risk appeared to be warranted to facilitate rapid maturing of the technology, leading to near-term commercialization. 


\section{ADVANCED HYBRID PARTICULATE COLLECTOR}

\subsection{PHASE II PLANNED WORK}

\subsection{Objectives for Phase II}

The overall project objective remains the same as for Phase I: to develop a highly reliable advanced hybrid particulate collector (AHPC) that can provide $>99.99 \%$ particulate collection efficiency for all particle sizes from 0.01 to $50 \mu \mathrm{m}$, is applicable for use with all U.S. coals, and is cost-competitive with existing technologies. The developmental objective for Phase II is to take the concept from Maturity Level II, which was achieved in Phase I, through Maturity Level III, engineering development scale. This will be achieved by increasing the scale of the AHPC size and the test duration by a factor of 45 to 50 and by utilizing full-scale components.

\subsection{Phase II Statement of Work}

\subsubsection{Task 1 - Project Management and Reporting}

The purpose of Task 1 is to separate the management aspects of the project from the design, construction, and experimental work. Since the project team includes W.L. Gore \& Associates, Inc., Allied Environmental Technologies, Inc., and the Energy \& Environmental Research Center (EERC), coordination of work among the three members and with the U.S. Department of Energy (DOE) will require dedicated project management for the life of the project. In addition to the project management responsibilities of Phase I, a further activity for Phase II is the selection of an appropriate site for the tests and to coordinate with the host personnel. Task 1 includes all project management activities associated with the project such as planning, coordination, communication, and reporting. An economic analysis of the AHPC based on the field results will be conducted under Task 1 and included with the final report.

\subsubsection{Task $2 a-$ Additional 5.7- $\mathrm{m}^{3} / \min (200-a c f m)$ Tests}

Additional 5.7- $\mathrm{m}^{3} / \mathrm{min}(200-\mathrm{acfm})$ tests were planned to help design the scaled-up unit with the appropriate geometric configuration. Approximately 2 weeks of additional testing were planned to determine if the AHPC could be designed in a more compact configuration than tested in Phase I without compromising performance. During the first week, Configuration 1 was to be evaluated for $8 \mathrm{hr}$. If this resulted in satisfactory performance equivalent to the Phase I results, Configuration 2 was to be evaluated for $8 \mathrm{hr}$. If the second configuration worked well, the test was to be extended to approximately $50 \mathrm{hr}$.

Configuration 3 was to be tested during a second week and again tested up to $50 \mathrm{hr}$ if results looked promising. The results from these additional $5.7-\mathrm{m}^{3} / \mathrm{min}(200-\mathrm{acfm})$ tests were intended to serve as a basis to help design the $255-\mathrm{m}^{3} / \mathrm{min}(9000-\mathrm{acfm})$ unit. 


\subsubsection{Task $2 b$ - Design of 255- $\mathrm{m}^{3} / \min (9000$-acfm) Field Demonstration AHPC}

The goal for the scaleup tests is to evaluate the AHPC under the most realistic conditions achievable, including the use of full-scale components where possible. $255 \mathrm{~m}^{3} / \mathrm{min}(9000 \mathrm{acfm})$ size represents a large, pilot-scale (2.4-MW electrical equivalent) unit but appears to provide the best combination of being large enough to allow meaningful tests with full-scale components, but yet small enough to be transportable and cost-effective.

\subsubsection{Task $2 c$ - Construction and Installation of $255-\mathrm{m}^{3} / \mathrm{min}$ (9000-acfm) Unit}

The AHPC vessel and ducting will be constructed at the EERC. The selection of the Phase II field site was to be made during the early design phase of the $255-\mathrm{m}^{3} / \mathrm{min}(9000$-acfm) AHPC unit. The AHPC unit is to be installed on a slipstream of a full-scale, coal-fired utility boiler.

\subsubsection{Task 3 - Field Testing of 255- $\mathrm{m}^{3} / \mathrm{min}(9000-a c f m)$ Unit}

The primary purpose of Phase II is to provide long-term operating data that can be used to scale up the AHPC for application to full-scale boilers rather than to test a number of variables. Approximately 6 months of testing are planned. One of the most important objectives is to demonstrate that longer-term bag life can be achieved when operating at an $\mathrm{A} / \mathrm{C}$ ratio of $3.7 \mathrm{~m} / \mathrm{min}(12 \mathrm{ft} / \mathrm{min})$, using commercially available bags that will be provided by W.L. Gore \& Associates. A second important objective is to demonstrate ultrahigh particulate collection over an extended time period. After initial shakedown, the only parameter that may change is the $\mathrm{A} / \mathrm{C}$ ratio. If operation at $3.7 \mathrm{~m} / \mathrm{min}(12 \mathrm{ft} / \mathrm{min})$ is highly successful after 5 months of operation, the A/C ratio will likely be increased to $4.9 \mathrm{~m} / \mathrm{min}(12 \mathrm{ft} / \mathrm{min})$ for the last month of testing. Extensive particulate monitoring to establish the fine-particle collection efficiency will be completed three times during the testing: near the beginning, at the middle, and near the end of the tests. Operational data will be recorded with a data logger and transmitted to the EERC via modem. At the end of the Phase II testing, if there is no need for further testing at the field site, the AHPC field unit will be disassembled and either returned to the EERC for storage or field-salvaged. If results from the field tests indicate commercial viability and there is interest in continued tests at the field site location, the EERC will seek additional commercial funding to continue the tests.

\subsection{PROJECT STATUS AND RESULTS}

\subsection{Selection of Field Test Site}

The main selection criteria for the field site demonstration were:

- An interest in the AHPC technology and a willingness to host the demonstration.

- Burning a coal that is representative of coals widely used in the United States.

- A reasonable distance from the EERC. 
- The long-term potential for a retrofit of the AHPC, if results look promising.

- Production of ash that is reasonably challenging for the AHPC.

Otter Tail Power Company has agreed to host the AHPC demonstration at its Big Stone Plant, located near Milbank, South Dakota. The plant is a single, 420-MW, cyclone-fired unit that burns a Powder River Basin subbituminous coal and has an electrostatic precipitator (ESP) for particulate control. Particulate sampling with a 6-stage multicyclone at the ESP inlet duct near the location where the duct tie-in would occur shows the dust loading to be in the range of 3.7 to 5.7 $\mathrm{g} / \mathrm{m}^{3}$, with a mass median particle size greater than $7 \mu \mathrm{m}$ and about $3 \%$ of the mass as submicron. Figure 1 is a log-probability plot of the two multicyclone runs. Since $70 \%$ of the dust was collected in the first cyclone, the mass median diameter of the distribution can be estimated only by extrapolation of the data to the $50 \%$ mass percentage. This extrapolation suggests a mass median diameter of about $20 \mu \mathrm{m}$, but this is most likely high because extrapolation to the edge of the graph implies that over $10 \%$ of the mass is larger than $100 \mu \mathrm{m}$. The extrapolation is based on the assumption of a perfect log-normal fit. Typically, few particles larger than 100 are seen in fly ash because large particles would tend to settle or impact further upstream. Plant data indicate that the ash is somewhat on the high-resistivity range and can be a challenge for the existing precipitator. The combination of fairly small particle size, higher-than-ideal resistivity, and reasonable dust loading should be a good test for the AHPC. In addition, the plant configuration should facilitate installation and operation of the AHPC unit. Since all of the selection criteria were met, the decision was made to conduct the field test at the Big Stone Plant. During a recent planned outage, the inlet and outlet duct taps for the AHPC slipstream were installed and blanked off. This will allow the installation of the AHPC next spring without shutting down the plant.

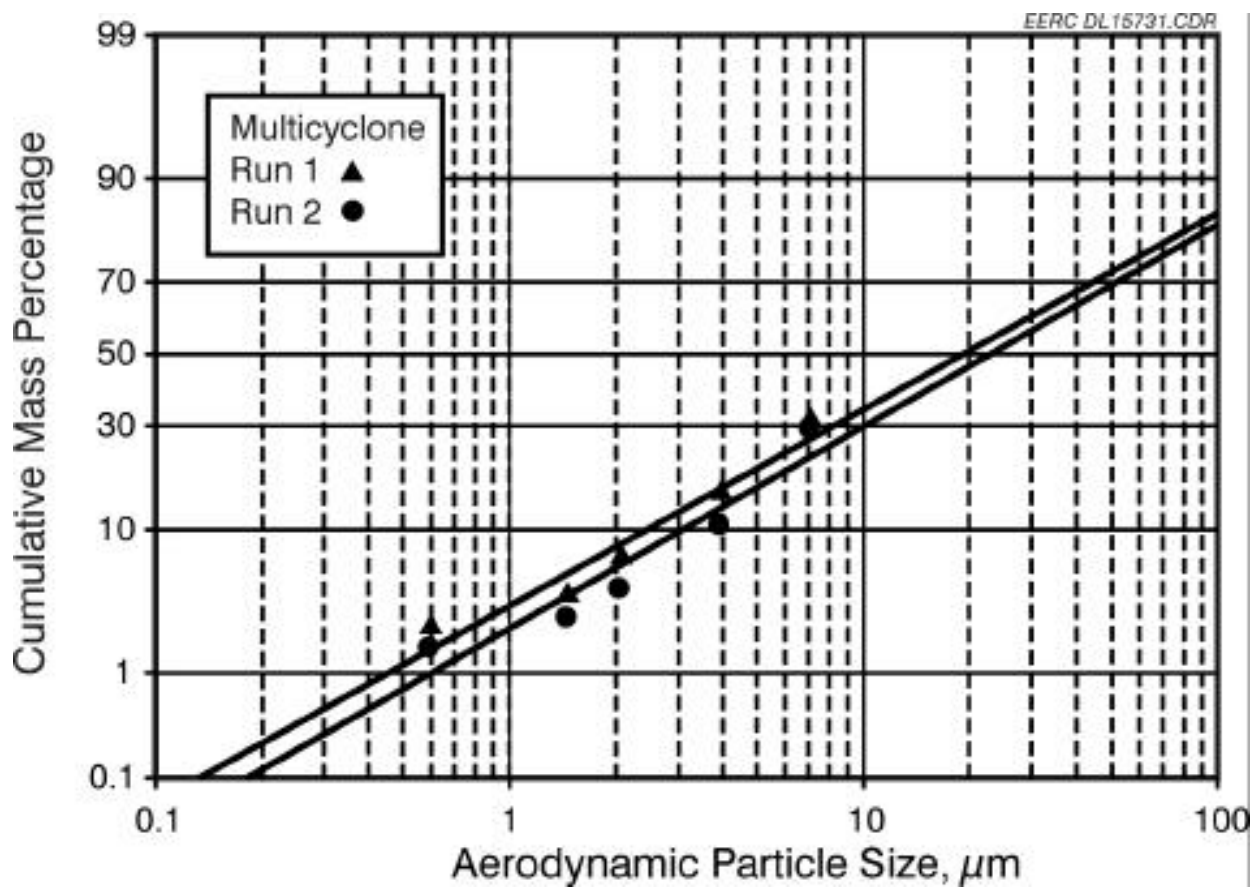

Figure 1. Particle-size distribution at the ESP inlet. 


\section{$2.2 \quad 5.7-\mathrm{m}^{3} / \mathrm{min}(200-a c f m)$ Pilot-Scale Tests}

The purpose of these tests, which were completed in July, was to evaluate AHPC performance with three different geometric configurations which could improve performance and/or make the AHPC vessel smaller than the configuration that was tested in Phase I.

\subsection{Configurations 1 and 2 Tests}

Configuration 1 (Run AB-599) was evaluated for 13 hours after which the AHPC was taken off-line and modified to Configuration 2 (Run AB-599) while the coal combustor remained operational. The test coal, a Powder River Basin subbituminous from the Absaloka mine, was the same as one of the coals tested in Phase I. Configuration 1 appeared to work better than any of the tests in Phase I. Bag cleaning was initiated at $2 \mathrm{kPa}$ as in Phase I, and only nine bag-cleanings were required for the 13-hour period (see Figure 2, 300-1100 minutes). When the AHPC was converted to Configuration 2, 20 bag-cleanings were required for the first 13 hours, which indicates a significant decrease in performance compared to the first configuration. There were some operational problems for this test as indicated by the drop in ESP current (Figure 2, 1700-2800 minutes). However, for the last 12 of the 36 hours (Figure 2, 2800-3500 minutes), operation was steady, with a bag-cleaning interval of about 30 minutes and a stable ESP current. The Configuration 2 results were as good as what was achieved in the Phase I 100-hr tests, so these results show that the AHPC can perform with the alternative configuration. However, since Configuration 1 appeared to provide much better performance than in Phase I, it is preferred to Configuration 2 for the larger $255-\mathrm{m}^{3} / \mathrm{min}$ (9000-acfm) unit.

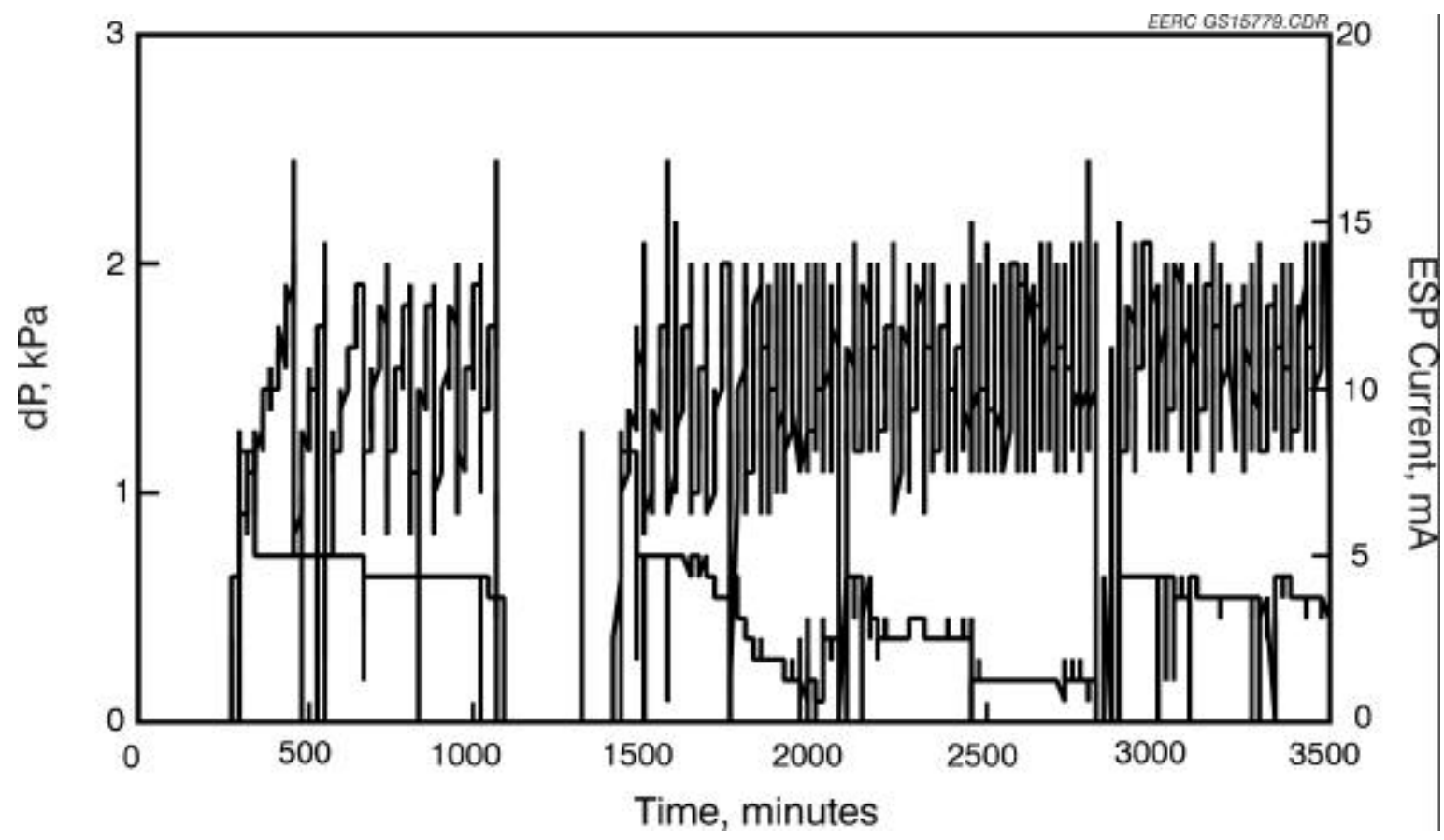

Figure 2. AHPC pressure drop and ESP current for Runs 598 and 599. 
A third geometric variation, designated as Configuration 3, was tested for 50 hours in Run AB-600. The pressure drop and ESP current for this run are shown in Figure 3, and the bag-cleaning interval is shown in Figure 4. The 50-hr test was completed without any major problems, and the unit was on-line continuously for the entire period. By the end of 13 hours, the bags were cleaned 17 times, which was not as good as Configuration 1. By the end of the test period, the bag-cleaning interval was about 30 minutes, which, again, was as good as the best performance demonstrated in Phase I. Near the end of the test, the ESP power was shut off to determine the effect on AHPC performance. As shown in Figure 4, the AHPC went into almost continuous cleaning, indicating a significant benefit of the ESP power. When the ESP power was applied again, the performance was restored to the previous level. This is an encouraging result, because it indicates that a momentary interruption in ESP power will not have a significant longterm effect on pressure drop. Since a good performance was achieved with all three of these configurations, there would be a strong basis for going with any of them for the $255-\mathrm{m}^{3} / \mathrm{min}$ (9000-acfm) unit. However, since the best performance was with Configuration 1, that configuration was chosen as the basis for design of the $255-\mathrm{m}^{3} / \mathrm{min}(9000-\mathrm{acfm})$ AHPC.

\subsection{Design, Construction, and Testing of $\left.255-\mathrm{m}^{3} / \mathrm{min}^{(9000-a c f m}\right)$ AHPC}

Design and construction of the field unit are progressing well. As of early November, the major steel components have been procured, and fabrication of the main vessel shell has started. The goal as stated in the work plan is to field-test the AHPC for 5000 hours, or about 6.5 months. The current schedule calls for completion of the field test by October 30, 1999, which means the field testing should start by April 1, 1999. The only planned independent experimental test variable is the $\mathrm{A} / \mathrm{C}$ ratio. The plan is to operate the $\mathrm{AHPC}$ at an $\mathrm{A} / \mathrm{C}$ ratio of $3.7 \mathrm{~m} / \mathrm{min}$

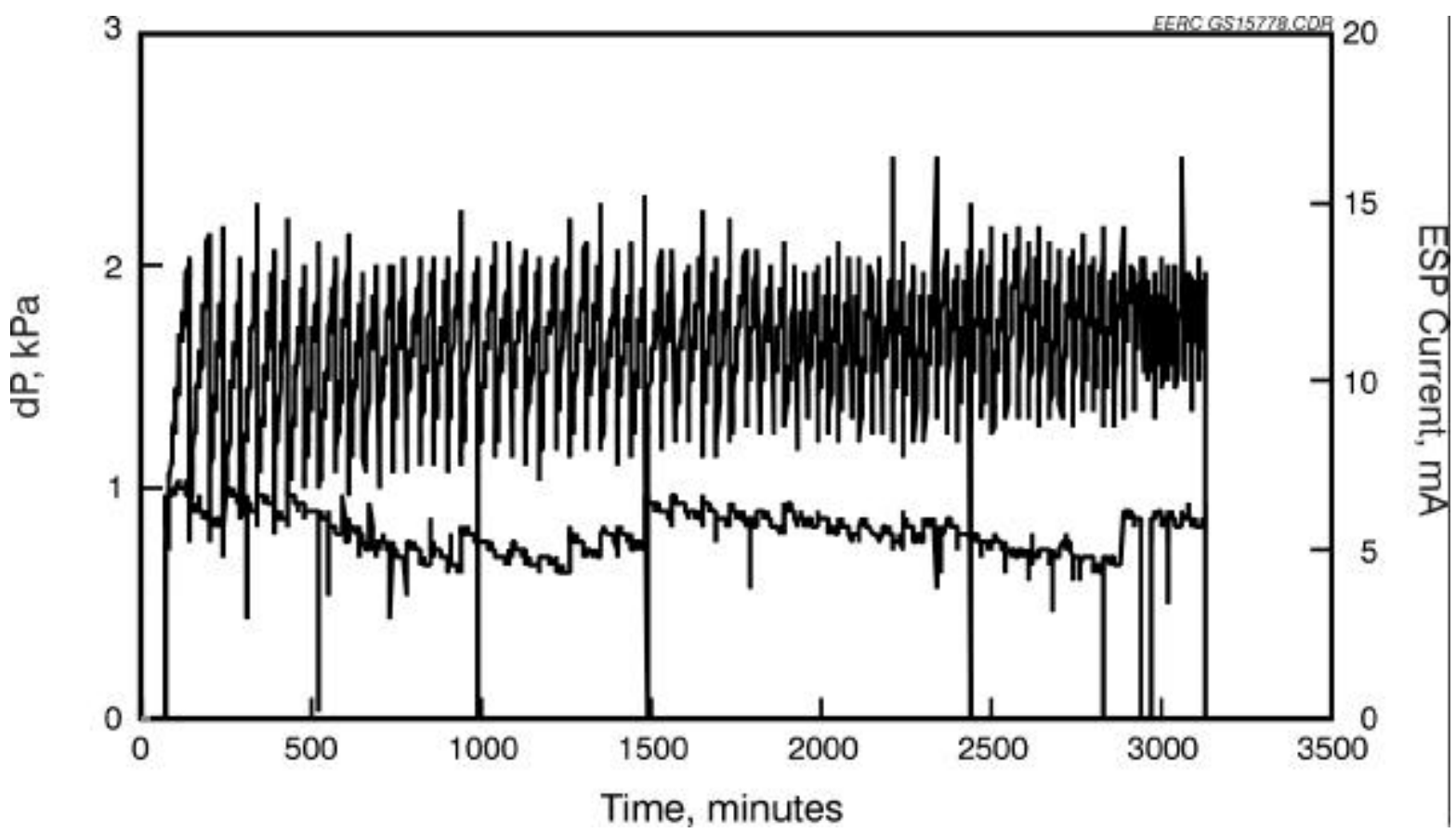

Figure 3. AHPC pressure drop and ESP current for Run 600. 


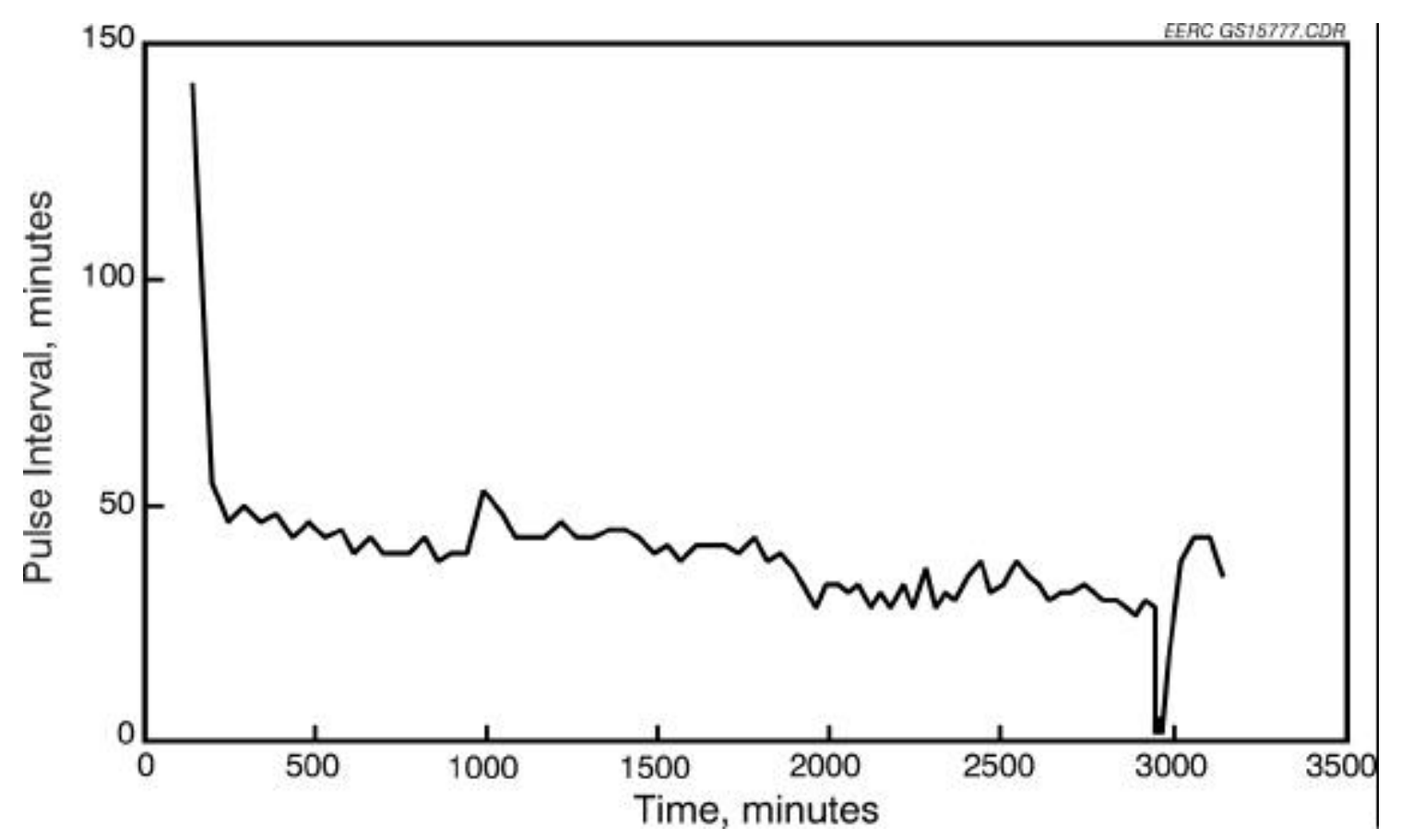

Figure 4. Bag cleaning interval for Run 600.

(12 ft/min) for the first 5.5 months, and then, if results are promising, increase the A/C ratio to 4.9 $\mathrm{m} / \mathrm{min}(16 \mathrm{ft} / \mathrm{min})$ for the last month. Extensive particulate emissions testing is planned three times, near the beginning, middle, and end of the test period. It should be recognized that the initial shakedown of the unit will likely require some adjustment of the operational variables, but once these are set, the goal is to prove the longer-term operability of the demonstration AHPC. 